\title{
Ternary nanoparticles composed of cationic solid lipid nanoparticles, protamine, and DNA for gene delivery
}

This article was published in the following Dove Press journal:

International Journal of Nanomedicine

17 August 2013

Number of times this article has been viewed

\author{
Sai-Nan $\mathrm{He}^{1}$ \\ Yun-Long $\mathrm{Li}^{1,2}$ \\ Jing-Jing Yan $^{2}$ \\ Wei Zhang² \\ Yong-Zhong $\mathrm{Du}^{2}$ \\ He-Yong Yu' \\ Fu-Qiang $\mathrm{Hu}^{2}$ \\ Hong Yuan ${ }^{2}$
}

'Women's Hospital, ${ }^{2}$ College of Pharmaceutical Sciences, School of Medicine, Zhejiang University, Hangzhou, People's Republic of China
Correspondence: Hong Yuan College of Pharmaceutical Sciences, Zhejiang University, 866 Yuhangtang Road, Hangzhou 310058, People's

Republic of China

Tel +86 57l 88208439

Fax +86 57I 88208439

Email yuanhong70@zju.edu.cn

He-Yong Yu

Women's Hospital, School of Medicine, Zhejiang University, 2 Xueshi Road, Hangzhou 310006, People's Republic of China

Tel +86 57| 8706 I50 I

Fax +86 57| 8706 I50 I

Email yuhy@zju.edu.cn
Background: The objective of this research was to design an effective gene delivery system composed of cationic solid lipid nanoparticles (SLNs), protamine, and Deoxyribonucleic acid DNA.

Methods: Cationic SLNs were prepared using an aqueous solvent diffusion method with octadecylamine as the cationic lipid material. First, protamine was combined with DNA to form binary protamine/DNA nanoparticles, and the ternary nanoparticle gene delivery system was then obtained by combining binary protamine/DNA nanoparticles with cationic SLNs. The size, zeta potential, and ability of the binary and ternary nanoparticles to compact and protect DNA were characterized. The effect of octadecylamine content in SLNs and the SLNS/DNA ratios on transfection efficiency, cellular uptake and cytotoxicity of the ternary nanoparticles were also assessed using HEK293 cells.

Results: When the weight ratio of protamine to DNA reached $1.5: 1$, the plasmid DNA could be effectively compacted and protected. The average hydrodynamic diameter of the ternary nanoparticles when combined with protamine increased from $188.50 \pm 0.26 \mathrm{~nm}$ to $259.33 \pm 3.44 \mathrm{~nm}$, and the zeta potential increased from $25.50 \pm 3.30 \mathrm{mV}$ to $33.40 \pm 2.80 \mathrm{mV}$ when the weight ratio of SLNs to DNA increased from $16 / 3$ to $80 / 3$. The ternary nanoparticles showed high gene transfection efficiency compared with Lipofectamine ${ }^{\mathrm{TM}}$ 2000/DNA nanoparticles. Several factors that might affect gene transfection efficiency, such as content and composition of SLNs, post-transfection time, and serum were examined. The ternary nanoparticles composed of SLNs with $15 \mathrm{wt} \%$ octadecylamine (50/3 weight ratio of SLNs to DNA) showed the best transfection efficiency $(26.13 \% \pm 5.22 \%)$ in the presence of serum. It was also found that cellular uptake of the ternary nanoparticles was better than that of the SLN/DNA and binary protamine/DNA nanoparticle systems, and DNA could be transported to the nucleus.

Conclusion: SLNs enhanced entry of binary protamine/DNA nanoparticles into the cell, and protamine protected DNA from enzyme degradation and transported DNA into the nucleus. Compared with Lipofectamine 2000/DNA nanoparticles, these cationic ternary nanoparticles showed relatively durable and stable gene transfection in the presence of serum.

Keywords: solid lipid nanoparticles, protamine, plasmid DNA, gene transfection, ternary nanoparticles

\section{Introduction}

Much research effort has been concentrated on gene therapy, because it is a field with great potential for the treatment of congenital and acquired disease, ${ }^{1}$ such as monogenic hypercholesterolemia ${ }^{2}$ and breast cancer. ${ }^{3}$

Nowadays, the success of gene therapy is principally limited by the low efficiency of vector systems. Historically, two opposing vector systems, ie, viral and nonviral, 
have been used for gene delivery. Nonviral vectors are mainly composed of cationic polymers and cationic lipids. They are being studied extensively in gene therapy as an attractive alternative to viral-based systems because of the decreased risks, such as oncogenicity or immunogenicity, easier manufacture, and lack of a DNA size limit. ${ }^{4,5}$ However, the gene transfection efficiency of nonviral vectors is still lower than that of their viral counterparts, so it is necessary to explore further optimal nonviral vectors for gene delivery in order to deliver therapeutic genes to target cells effectively with minimal cell toxicity.

It is known that gene transfection in nonviral systems is conditioned by barriers to intracellular trafficking of the vectors from the exterior of the cell to the nucleus. ${ }^{6}$ Endocytosis has been considered to be the major cellular entry mechanism for cationic nanoparticles. ${ }^{7,8}$ Therefore, to achieve efficient expression of the target gene, such nanoparticles must overcome limiting barriers, including internalization into cells, ${ }^{9}$ gene transfer from the endosome to the cytosol, ${ }^{10}$ and transport of the target gene to the nucleus. ${ }^{11}$

Numerous efforts have been made to establish effective and stable gene transfection systems. Several ternary systems have been reported, and were made by compacting Deoxyribonucleic acid (DNA) with cationic condensing molecules first and then adding the cationic liposome. On the one hand, cationic condensing compounds, such as protamine ${ }^{12,13}$ and tat peptide, ${ }^{14,15}$ are able to encapsulate a target gene into a compact structure and thereby prevent it against degradation by nuclease. Some of these peptides also function as membrane-disrupting peptides and can destabilize endosomal membranes to increase the efficiency of gene transfection. ${ }^{15}$ These ternary systems also form small condensed particles that are stable and less prone to the aggregation observed with some lipid-DNA nanoparticles, ${ }^{13}$ and are suitable for use in vivo. On the other hand, the lipid portion of ternary nanoparticles is essential for efficient transfection, because this permits entry of DNA nanoparticles into the cell via interactions with the cell membrane ${ }^{16}$ and induces fusion with the endosome membrane to promote gene transfer into the cytosol. ${ }^{17}$

In this study, protamine, a compound approved by the US Food and Drug Administration, ${ }^{18}$ was chosen as the condensing peptide because it is a natural polycation existing in most vertebrate sperm cells, and can condense DNA into nanoparticles, with a particular structure in the head of sperm. ${ }^{19,20}$ Such highly compact nanoparticles are resistant to nuclease and can orientate DNA to the nucleus of the ovum. All these characteristics make protamine attractive for application in transfection. Protamine has been shown by other researchers to enhance cationic lipid-mediated transfection. ${ }^{12,21-23}$ Addition of protamine, containing nuclear localization signals, improved nuclear entry of DNA. ${ }^{23}$ However, protamine is a hydrophilic protein, so encounters difficulty crossing the cell membrane. ${ }^{24}$ Cationic lipid was replaced by solid lipid nanoparticles (SLNs) for investigation of its advantages, such as rapid uptake by cells, protection of the incorporated compound against chemical degradation, and potential for large-scale production. ${ }^{25}$ SLNs have already been utilized as drug delivery systems, ${ }^{26,27}$ and their use in gene therapy is attracting increasing attention. ${ }^{12,21}$ However, their transfection efficiency is low in comparison with that of conventional viral agents. In previously published research, ${ }^{28}$ we used a nanostructured lipid carrier to form ternary nanoparticles, and the surface charge was negative. Given that cationic SLNs have better ability in terms of endocytosis, in this study we used cationic SLNs to form ternary nanoparticles to test their gene transfection efficiency. Vighi et $\mathrm{al}^{29}$ also used cationic SLNs as a gene vector and the protamine was used as a transfection promoter. It was found that the lower the protamine amount on the surface of the SLN, the lower the efficiency of transfection.

In this research, an SLN/protamine/DNA gene delivery system was designed to improve transfection efficiency. Solid lipid nanoparticles were prepared using an aqueous solvent diffusion method. First, monostearin and octadecylamine were used as solid lipids. Poloxamer $188(0.1 \%$, w/v) solution was used as the aqueous phase. Monostearin was chosen because it fuses easily with the anionic cell membrane, facilitating uptake by cells. ${ }^{27}$ The effect of protamine on gene transfection efficiency mediated by SLNs was also investigated. Gene transfection experiments were performed, using human embryonic kidney (HEK) 293 cells as the cell model and pEGFP-N1 and the luciferase reporter gene as reporter genes. The effects of composition of SLNs, post-transfection time, and serum on gene transfection efficiency were examined in detail. The ability of protamine to compact and protect DNA from nuclease and its cellular uptake capacity were then investigated to explore the mechanism responsible for higher transfection efficiency.

\section{Materials and methods Materials}

Monostearin (Shanghai Chemical Reagent Co, Ltd, Shanghai, People's Republic of China) was used as the solid lipid material for preparation of SLNs. Octadecylamine was purchased from Fluka (Sigma-Aldrich, St Louis, MO, USA), and 
Poloxamer 188 from Shenyang Jiqi Pharmaceutical Co, Ltd, (Shenyang, People's Republic of China). Protamine sulfate and DNA (order of DNA, 5'-CCCAGCCTTCCAGCTCCTTG-3') labeled with a red dye (ROX) were purchased from Shanghai Sangon Biological Engineering Technology and Services Co, Ltd, (Shanghai, People's Republic of China). Hoechst 33342 (Sigma-Aldrich) was used as a staining reagent for the nucleus. Fluorescein isothiocyanate (FITC) was purchased from Acros Organic (Fair Lawn, NJ, USA), and 3-(4, 5-dimethylthiazol-2-yl)-2, 5-diphenyl-tetrazolium bromide (MTT) from Sigma-Aldrich. Deoxyribonuclease I (DNase I) was sourced from Takara Biotechnology (Dalian) Co, Ltd, (Mountain View, CA, USA). Dulbecco's Modified Eagle's Medium and trypsin-EDTA were purchased from Gibco BRL (Gaithersberg, MD, USA). A bicinchoninic acid protein assay kit was obtained from the Beyotime Institute of Biotechnology (Jiangsu, People's Republic of China). The luciferase assay agent was provided by Chemi \& BioLuminescence (Shanghai, People's Republic of China). Fetal bovine serum was purchased from Sijiqing Biologic Co, Ltd, (Zhejiang, People's Republic of China), and pEGFP-N1 (4.7 kb) encoding a green fluorescent protein gene and the luciferase gene were donated by the National Institutes of Health (Bethesda, MD, USA). Ethanol and other chemicals were of analytical reagent grade.

HEK293 cells were provided by the National Institutes of Health. The cells were cultured at $37^{\circ} \mathrm{C}$ with $5 \% \mathrm{CO}_{2}$ under fully humidified conditions. The culture medium was Dulbecco's Modified Eagle's Medium supplemented with $10 \%$ fetal bovine serum, $100 \mathrm{U} / \mathrm{mL}$ penicillin, and $100 \mu \mathrm{g} / \mathrm{mL}$ streptomycin.

\section{Preparation of SLNs by conventional solvent diffusion method}

SLNs were prepared using the aqueous solvent diffusion method in an aqueous system, as reported elsewhere. ${ }^{27}$ Briefly, $50 \mathrm{mg}$ of monostearin and $0-10 \mathrm{mg}$ of octadecylamine were completely dissolved in $5 \mathrm{~mL}$ of ethanol in a water bath under $60^{\circ} \mathrm{C}$. The resulting organic solution was dispersed rapidly in $50 \mathrm{~mL}$ of Poloxamer 188 solution $(0.1 \%$, $\mathrm{w} / \mathrm{v}$ ) under mechanical stirring at $400 \mathrm{rpm}$ for 5 minutes. The pre-emulsion (containing melted lipid droplets) obtained was then cooled to room temperature until an SLN dispersion was obtained. The $\mathrm{pH}$ of the dispersion was adjusted to 1.2 by adding $0.1 \mathrm{M}$ hydrochloric acid to precipitate the SLNs. After centrifugation (20,000 rpm for 15 minutes), the SLNs obtained were redispersed in $50 \mathrm{~mL}$ of Poloxamer 188 solution $(0.1 \%, \mathrm{w} / \mathrm{v})$ and the $\mathrm{pH}$ was adjusted to neutral by adding $0.2 \mathrm{M} \mathrm{NaOH}$ solution.

\section{Preparation and characterization of protamine/DNA and ternary nanoparticles}

Protamine/DNA nanoparticles containing different weight ratios of protamine to DNA were first prepared by vortically mixing DNA solution with appropriate amounts of protamine in distilled water for 30 seconds, and then allowing them to stand for 30 minutes at room temperature. Ternary SLN/ protamine/DNA nanoparticles containing different weights of SLNs were prepared by mixing appropriate amounts of SLN nanosuspension with a solution containing binary protamine/ DNA nanoparticles for 30 seconds, and then allowing this mixture to stand for 30 minutes at room temperature. The average hydrodynamic diameter, zeta potential, and polydispersity index of the SLN/protamine/DNA nanoparticles were measured by dynamic light scattering using a Zetasizer (3000HS, Malvern Instruments Ltd, Malvern, UK).

\section{Evaluation of surface morphology}

Morphologic examination of protamine, binary protamine/ DNA nanoparticles, SLNs, and ternary SLN/protamine/DNA nanoparticles was done using atomic force microscopy (SPA 3800 N, Seiko, Tokyo, Japan) in tapping mode using a high resonant frequency $\left(\mathrm{F}_{0}=129 \mathrm{kHz}\right)$, pyramidal cantilevers, and silicon probes with a force constant of $20 \mathrm{~N} / \mathrm{m}$. Scan speeds were set at $2 \mathrm{~Hz}$. The samples were diluted with distilled water and deposited onto freshly cleaved mica plates, followed by vacuum-drying for 24 hours at $25^{\circ} \mathrm{C}$.

The morphology of the ternary nanoparticles was examined further by transmission electron microscopy (JEM1230EX, JOEL, Tokyo, Japan). Samples were prepared by placing a drop of the ternary nanoparticle suspension onto a copper grid, followed by negative staining with one drop of a $2 \%$ aqueous solution of sodium phosphotungstate for contrast enhancement. The air-dried samples were then observed directly by transmission electron microscopy.

\section{Gel retardation assay}

The potential of the binary nanoparticles (containing different weight ratios of protamine to DNA) and ternary nanoparticles (containing different amounts of SLNs) to condense DNA ( $1 \mu \mathrm{g} /$ well) was investigated on $0.8 \%$ agarose gel with a current voltage of $120 \mathrm{~V}$ for 30 minutes in Tris-acetate-EDTA buffer solution (40 mM Tris- $\mathrm{HCl}, 1 \%$ (v/v) acetic acid, $1 \mathrm{mM}$ EDTA). Images were obtained using an ultraviolet transilluminator and a digital imaging system (GL 200, Kodak, Windsor, CO, USA). 


\section{DNase I protection assay}

For the DNase I protection assay, the binary and ternary nanoparticles (DNA, $1 \mu \mathrm{g} /$ well) were incubated in a buffer solution (10 mM Tris- $\mathrm{HCl}, 150 \mathrm{mM} \mathrm{NaCl}, 1 \mathrm{mM} \mathrm{MgCl}$, $\mathrm{pH}$ 7.4) containing 20 units of DNase I. The change in ultraviolet absorbance at $260 \mathrm{~nm}$ was measured at different time intervals using an ultraviolet spectrophotometer (Ultrospec 5300pro, ImageQuant, Piscataway, NJ, USA).

\section{In vitro gene transfection test}

HEK293 cells were seeded in 24-well plates at a density of $1 \times 10^{5}$ cells/well in $1 \mathrm{~mL}$ of complete medium. After incubation for 24 hours, the medium was replaced by $0.5 \mathrm{~mL}$ of serum-free or $10 \%$ fetal bovine serum containing binary or ternary nanoparticles (pDNA, $2 \mu \mathrm{g} /$ well), and then incubated for a further 6 hours. The medium was then replaced with $1 \mathrm{~mL}$ of fresh complete medium, and incubation was continued for a further 72 hours at $37^{\circ} \mathrm{C}$. A gene transfection test using Lipofectamine ${ }^{\mathrm{TM}}$ 2000/DNA nanoparticles was performed as a positive control following the manufacturer's protocol.

Luciferase gene expression was assessed by measuring luciferase activity with a chemiluminescence detector (FB12, Sirius, Berthold Detection Systems, Hannover, Germany). Relative light units were normalized to protein concentration in the cell extracts, and measured using the bicinchoninic acid method with an enzyme-linked immunosorbent assay plate reader (Model 680, Bio-Rad Laboratories, Hercules, CA, USA).

Transfection efficiency was also evaluated by FACScan analysis. After 24, 48, and 72 hours of incubation, the cells were washed with cold Dulbecco's phosphate-buffered saline and harvested by addition of trypsin-EDTA solution. Next, $1 \mathrm{~mL}$ of phosphate-buffered saline was added and the cells were centrifuged at $1,000 \times \mathrm{g}$ for 4 minutes. The pellet was then suspended in phosphate-buffered saline containing $2 \%$ formalin and analyzed on a FACScan flow cytometer (FACSCalibur, Becton Dickinson, BD Biosciences, Franklin Lakes, NJ, USA). Determination of green fluorescent protein-positive events was performed using a standard gating technique. The cells were also viewed directly under a fluorescent microscope (Olympus America, Melville, NY, USA).

\section{Cell growth inhibition assay}

The effects of the SLNs and ternary nanoparticles on inhibition of cell growth were determined by MTT assay, with HEK293 cells used as the cell model. The cells were seeded in 24-well plates at a density of $1 \times 10^{5}$ cells/well and incubated for 24 hours prior to addition of SLNs and ternary nanoparticles. The medium containing SLNs and ternary nanoparticles was replaced by fresh complete medium after 6 hours of incubation. After further incubation for 72 hours, the medium was replaced with complete medium containing $200 \mu \mathrm{g} / \mathrm{mL}$ MTT, and incubated for a further 4 hours. Absorbance was then measured at $570 \mathrm{~nm}$ using the enzymelinked immunosorbent assay plate reader. Untreated cells were used as controls. Growth assays were performed in triplicate. Cell viability was calculated using the following equation:

$$
\begin{aligned}
\text { Cell viability }(\%)= & \text { OD570 }(\text { sample }) / \\
& \text { OD570 }(\text { control }) \times 100
\end{aligned}
$$

\section{Cellular uptake of DNA and location of ternary nanoparticles}

ROX-labeled DNA was used to investigate trafficking of DNA inside the cells. SLNs loaded with octadecylamineFITC were synthesized using a previously reported method. ${ }^{30}$ The cells were seeded in 24-well plates at a density of $1 \times 10^{5}$ cells/well in $1 \mathrm{~mL}$ of complete medium. After incubation for 24 hours, the medium was replaced with $0.5 \mathrm{~mL}$ of medium containing DNA, binary nanoparticles, or ternary nanoparticles, and incubated for a further 6 hours. Prior to observation of the samples under a microscope, the cell nuclei were labeled with Hoechst 33342 for 15 minutes and then washed three times with phosphate-buffered saline. Images were captured using a fluorescent microscope (Olympus America). Observations and image capturing were done using a $20 \times$ objective.

\section{Statistical analysis}

The results are reported as the mean \pm standard deviation. Statistical analysis between different groups was done using the non-paired $t$-test. Differences were considered to be statistically significant if $P$ was $<0.05$.

\section{Results and discussion Preparation of ternary SLN/protamine/ DNA nanoparticles}

SLNs containing different amounts of octadecylamine were prepared using the solvent diffusion method. Ternary SLN/ protamine/DNA nanoparticles were then prepared by mixing appropriate amounts of SLNs, protamine, and DNA. The size and zeta potential of the nanoparticles was measured using a dynamic light scattering technique. SLNs with $15 \mathrm{wt} \%$ octadecylamine had an average size of $112.17 \pm 4.65 \mathrm{~nm}$ 
and a zeta potential of $42.7 \pm 0.8 \mathrm{mV}$. Binary protamine/ DNA nanoparticles $(1.5: 1, \mathrm{w} / \mathrm{w})$ had an average size of $125.43 \pm 3.44 \mathrm{~nm}$ and a zeta potential of $6.6 \pm 1.0 \mathrm{mV}$. Figure 1A shows the relationship of average hydrodynamic diameter, zeta potential, and weight ratio of SLNs (15 wt \% octadecylamine) with DNA in the ternary nanoparticles. When the weight ratio of SLNs to DNA increased from 16/3 to 80/3, the size increased from $188.50 \pm 0.26 \mathrm{~nm}$ to $259.33 \pm 3.44 \mathrm{~nm}$ and the zeta potential increased from $25.50 \pm 3.30 \mathrm{mV}$ to $33.40 \pm 2.80 \mathrm{mV}$. The ternary nanoparticles also showed a decrease in size distribution with increasing weight ratio of SLNs to DNA (Figure 1B). Nanoparticles have an affinity for positively and negatively charged molecules because of their large surface energy. ${ }^{31,32}$ Although the binary protamine/ DNA nanoparticles and SLNs were positively charged, the zeta potential of the binary protamine/DNA nanoparticles was relatively low, and ternary nanoparticles could be formed by nonspecific absorption between biomacromolecules (ie, binary nanoparticles) and SLNs.

Atomic force microscopy was used to investigate the morphology of the binary and ternary nanoparticles. Figure $2 \mathrm{~A}-\mathrm{C}$ shows atomic force microscopic images of the binary protamine/DNA (1.5:1, w/w) nanoparticles,
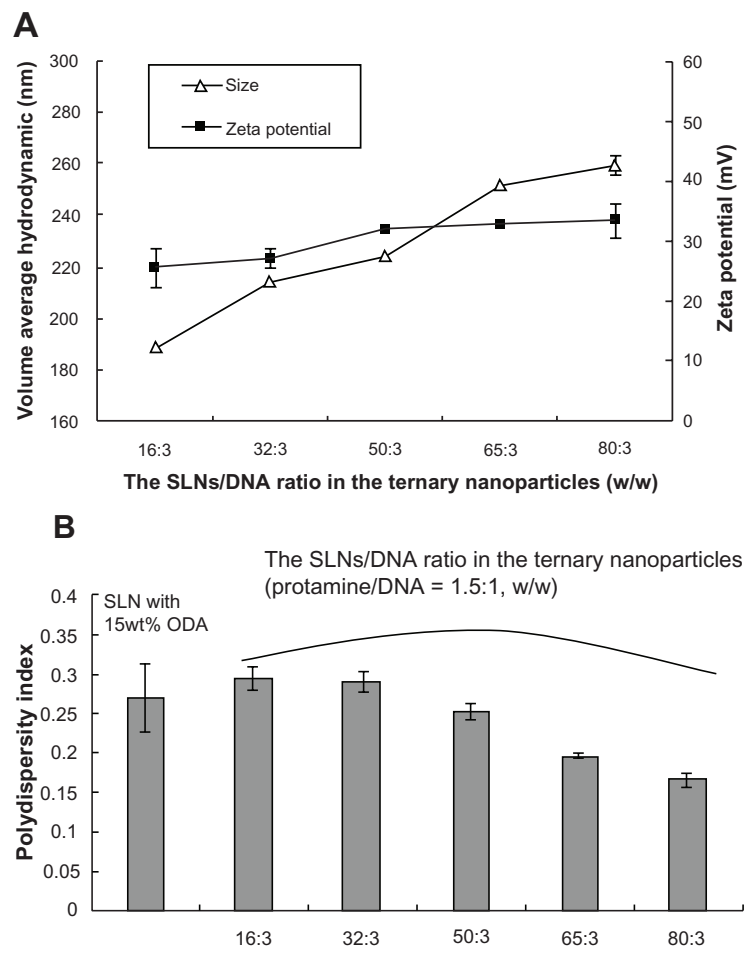

Figure I Average hydrodynamic diameter, zeta potential, and polydispersity index of SLN/protamine/DNA nanoparticles containing different amounts of SLNs to DNA (protamine/DNA, I.5:I, w/w).

Abbreviations: SLN, solid lipid nanoparticles; DNA, deoxyribonucleic acid; ODA, octadecylamine. blank SLNs (15 wt\% octadecylamine), and ternary SLN/ protamine/DNA nanoparticles (weight ratio of SLNs to protamine and DNA, 50/4.5/3), respectively. SLNs prepared using the solvent diffusion method were less than $100 \mathrm{~nm}$ in diameter, with a smooth surface morphology and a spherical shape (Figure 2B). The aqueous solution of protamine was seen to cover the mica plates entirely and to form a lamellar structure less than $0.5 \mathrm{~nm}$ in size (data not shown), whereas the binary protamine/DNA nanoparticles formed spherical, round-shaped compounds (Figure 2A) with an average size of about $100 \mathrm{~nm}$. The size of the ternary SLN/protamine/DNA nanoparticles was slightly greater than that of the binary ones and the blank SLNs (Figure 2C).

Topographic imaging using transmission electron microscopy also showed the structure of the binary protamine/ DNA (1.5:1, w/w) nanoparticles, blank SLNs (15 wt\% octadecylamine), and ternary SLN/protamine/DNA nanoparticles (Figure 2D-F). They were observed to form small spherical particles, and the size of the tested nanoparticles corresponded to the results determined by atomic force microscopy.

\section{Gel retardation assay}

The ability of the binary, SLN/DNA, and ternary nanoparticles to condense DNA was analyzed by agarose gel electrophoresis. Complete retardation of the binary protamine/DNA nanoparticles was observed when the weight ratio was above 1.0 (Figure $3 \mathrm{~A}$ ). In our previous research, we investigated the DNA condensation ability of SLNs, and showed that SLNs with $10 \mathrm{wt} \%$ or $15 \mathrm{wt} \%$ octadecylamine could completely retard DNA migration when the weight ratio of SLNs to DNA was above 3 (data not shown). Moreover, when the weight ratio of protamine to DNA was reduced to $0.5: 1$ and the weight ratio of SLNs to DNA in SLN/protamine/DNA nanoparticles was fixed at 3, stable nanoparticles could also be formed, and the DNA could be condensed completely (Figure 3B).

\section{DNase I protection assay}

The effect of protection to pDNA from nuclease degradation was examined using DNase I as a model enzyme. The results are shown in Figure 3C, which clearly demonstrates that naked plasmid DNA was degraded after 15 minutes. SLN/ DNA nanoparticles (with $15 \mathrm{wt} \%$ octadecylamine) could not protect the plasmid DNA from enzyme degradation efficiently, and the weight ratio of SLNs to DNA was increased to $50 / 3$. Combined with the gel retardation results for SLN/ DNA nanoparticles, it was found that although the cationic 

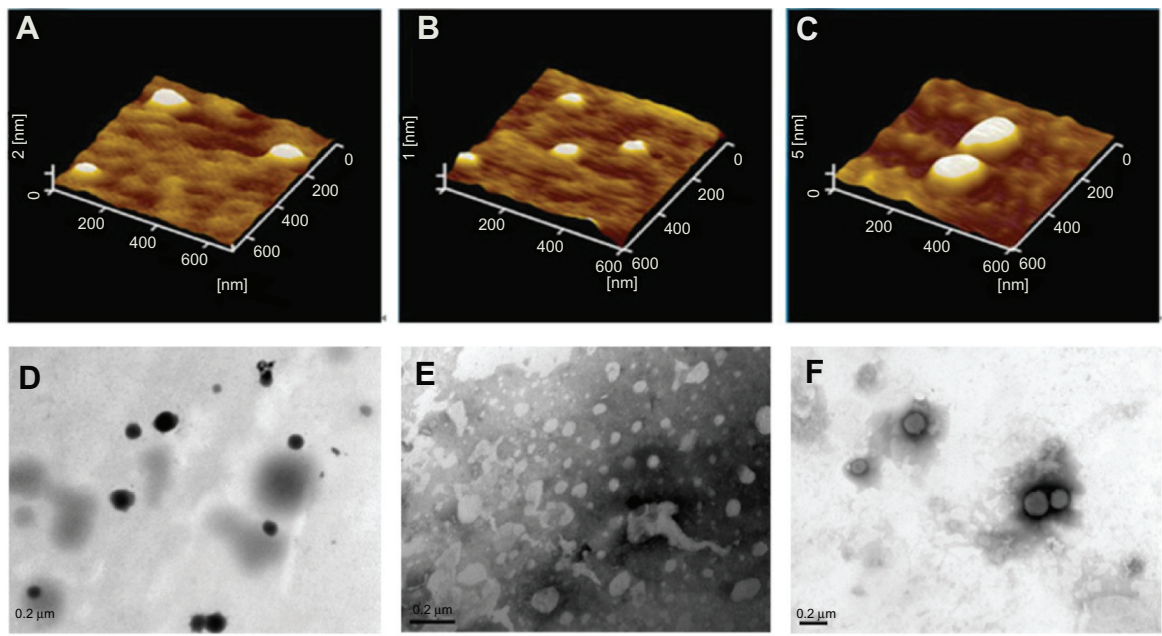

Figure 2 Atomic force microscopic images of (A) binary protamine/DNA nanoparticles (I.5:I, w/w), (B) SLN with I5 wt\% ODA, (C) SLN/protamine/DNA nanoparticles (SLNs with 15 wt\% ODA/protamine/DNA, 50:4.5:3, w/w/w), transmission electron microscopic images of (D) binary protamine/DNA nanoparticles, (E) SLNs with I5 wt\% ODA (I.5:I, w/w), and (F) SLN/protamine/DNA nanoparticles (SLNs with I 5 wt\% ODA/protamine/DNA, 50:4.5:3, w/w/w).

Abbreviations: ODA, octadecylamine; SLNs, solid lipid particles; DNA, deoxyribonucleic acid.

SLNs could compact plasmid DNA, they could not protect the DNA from degradation. However, binary protamine/DNA nanoparticles $(1.5: 1, \mathrm{w} / \mathrm{w})$ and ternary SLN/protamine/DNA nanoparticles $(50: 4.5: 3, \mathrm{w} / \mathrm{w} / \mathrm{w})$ provided powerful protection after 30 minutes. This indicates that protection of plasmid DNA against nucleases could be achieved after incorporating protamine, which is a requisite for efficient gene delivery in vivo and in vitro. ${ }^{33}$

\section{In vitro gene transfection}

Intracellular expression of plasmid DNA (pEGFP-N1) was examined using fluorescent microscopy and flow cytometry.

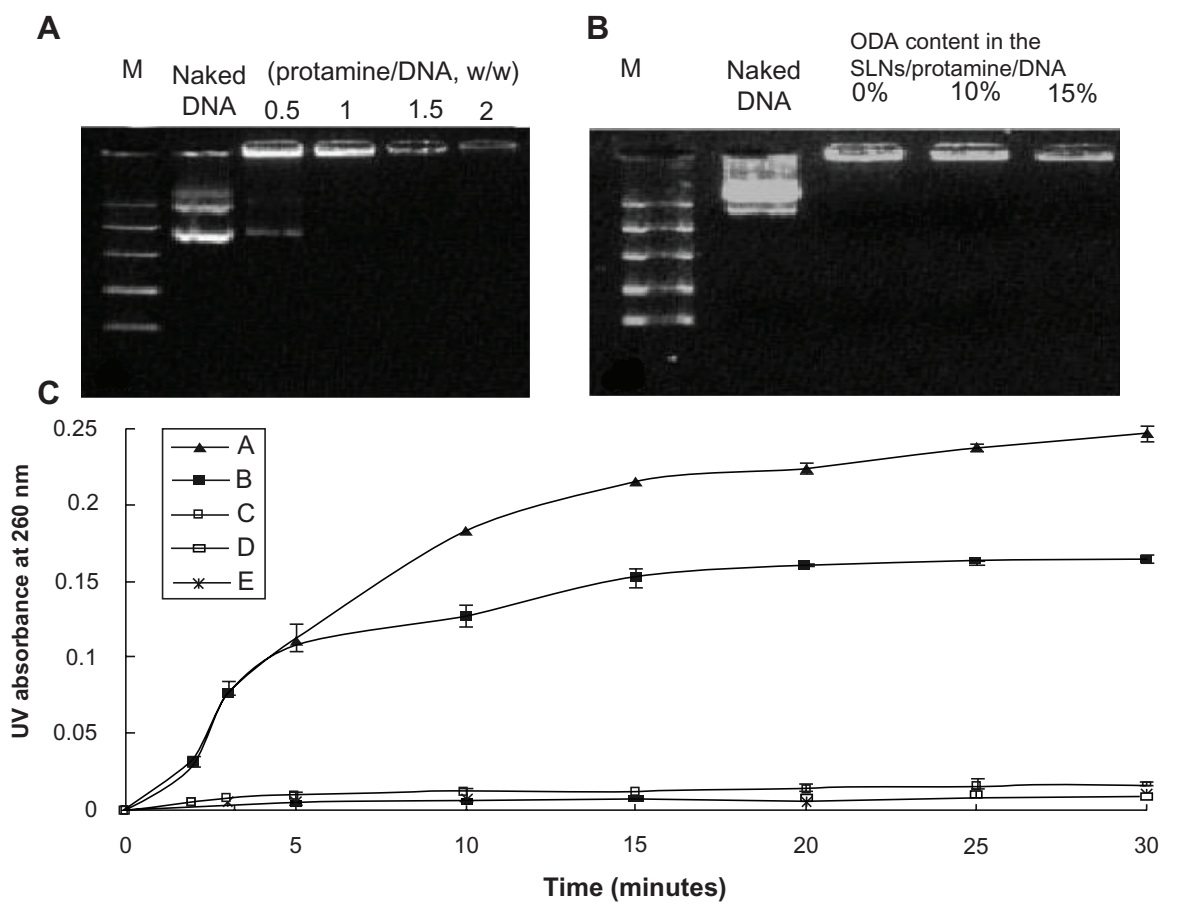

Figure $3 \mathrm{Gel}$ retarding (A and $\mathbf{B})$ and DNase I degradation assay (C) of protamine/DNA nanoparticles and SLN/protamine/DNA nanoparticles. In (B), lanes 3, 4, and 5 represent SLN/protamine/DNA nanoparticles prepared with SLNs containing 0 wt\%, 10 wt\%, or I5 wt\% ODA (w/w/w, 3:0.5:I). (C) Line A represents naked DNA as a control, line B represents SLN/DNA nanoparticles (SLNs with $15 \mathrm{wt} \%$ ODA/DNA, 50:3, w/w), line C represents binary protamine/DNA nanoparticles at a weight ratio of I.5:I, line D represents SLN/protamine/DNA nanoparticles (SLNs with 15 wt\% ODA/protamine/DNA, 50:4.5:3, w/w/w), and line E represents SLN/protamine/DNA nanoparticles (SLNs with 0 wt\% ODA/protamine/DNA, 50:4.5:3, w/w/w).

Abbreviations: M, marker; DNA, deoxyribonucleic acid; ODA, octadecylamine; SLNs, solid lipid particles. 
Plasmid pGL-3 was used as the luciferase reporter gene, and a luciferase expression assay was carried out. Moreover, the effects of serum, ratio of SLNs to DNA, content of octadecylamine in SLNs, and post-transfection time on gene transfection efficiency were investigated.

\section{Effect of SLN content in ternary nanoparticles}

Fixing the weight ratio of protamine to DNA at 1.5:1, the gene transfection efficiency of the ternary nanoparticles containing different weight ratios of SLNs with $15 \mathrm{wt} \%$ octadecylamine to DNA were examined. The results are shown in Figure 4. It is clear that the best transfection was obtained when the SLN/protamine/DNA content was optimal, ie, containing concentrations of $50 \mu \mathrm{g} / \mathrm{mL}, 4.5 \mu \mathrm{g} / \mathrm{mL}$, and $3.0 \mu \mathrm{g} / \mathrm{mL}$ for SLNs, protamine, and DNA, respectively. From the results of flow cytometry, it was calculated that the percentage of cells transfected was $26.13 \% \pm 5.22 \%$ and was nearly half that of Lipofectamine 2000/DNA (55.02\% $\pm 10.93 \%)$ without serum. Transfection efficiency decreased when the SLN content in the ternary nanoparticles was increased further, which may result from the toxicity at high doses and larger size (Figure 4).

\section{Effect of octadecylamine content in SLNs}

SLNs with the same monostearin content but different percentages of octadecylamine were prepared, and gene transfection experiments were carried out using SLN/protamine/ DNA nanoparticles with SLNs containing $0 \mathrm{wt} \%, 5 \mathrm{wt} \%$, $10 \mathrm{wt} \%, 15 \mathrm{wt} \%$, and $20 \mathrm{wt} \%$ octadecylamine. Each assay was done using the same content of binary protamine/DNA nanoparticles $(4.5 \mu \mathrm{g} / \mathrm{mL}$ protamine and $3.0 \mu \mathrm{g} / \mathrm{mL}$ DNA) and $50 \mu \mathrm{g} / \mathrm{mL}$ SLNs (monostearin content $50 \mu \mathrm{g} / \mathrm{mL}$ ). The results are shown in Figure 5. The transfection efficiency

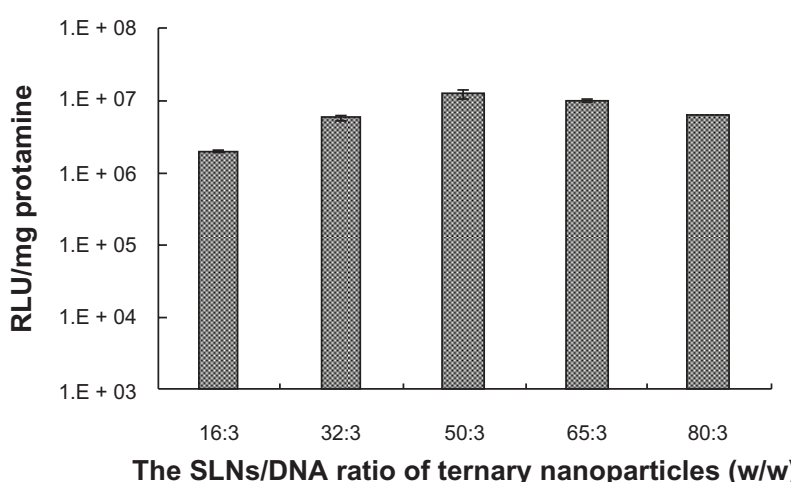

Figure 4 Effect of amounts of SLNs on gene transfection of SLN/protamine/DNA nanoparticles when the weight ratio of SLNs with $15 \mathrm{wt} \%$ ODA to DNA increases from 16:3 to 80:3 with a weight ratio of protamine to DNA of 1.5:I.

Abbreviations: ODA, octadecylamine; SLNs, solid lipid particles; DNA, deoxyribonucleic acid; RLU, relative luminescence units.
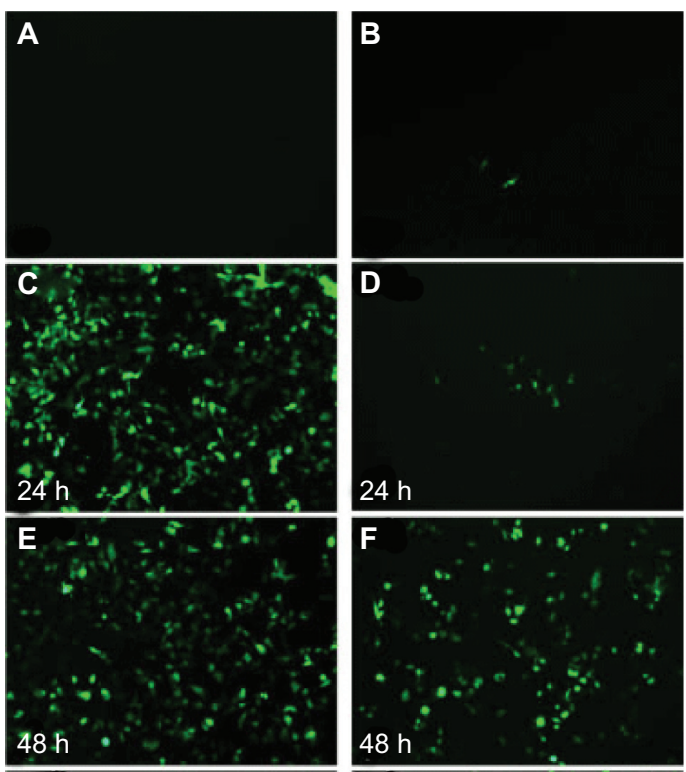

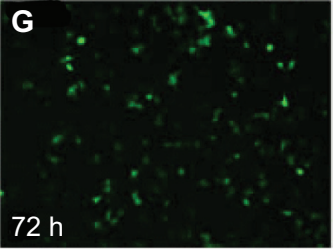

Lipofectamine $^{\mathrm{TM}}$ 2000/DNA
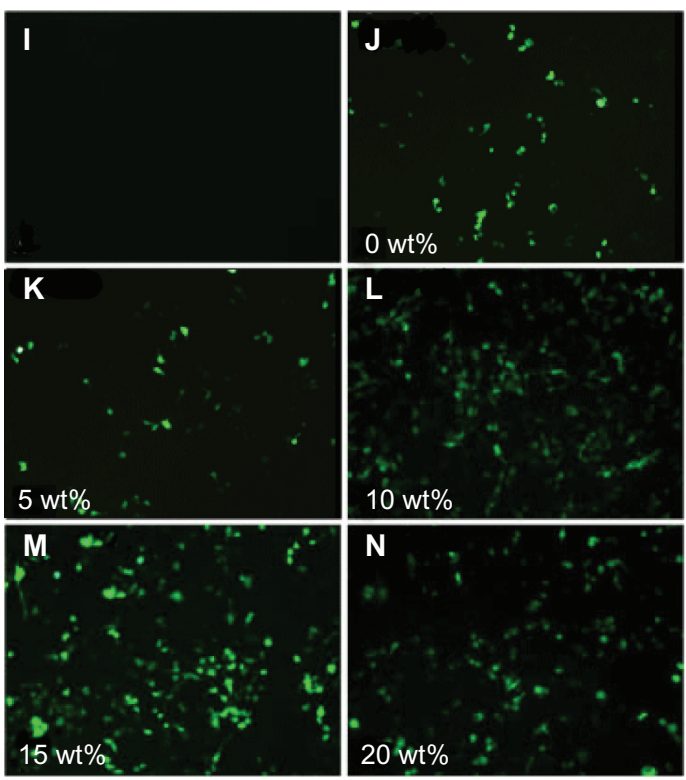

SLNs with different ODA content/protamine/DNA (gene transfection at $72 \mathrm{~h}$ )

Figure 5 Fluorescent microscopy of HEK293 cells transfected by PEGFP-NI. (A) Negative control (naked DNA only), (B) transfection with protamine/DNA nanoparticles for 72 hours, (C, E and G) cells transfected with Lipofectamine ${ }^{\text {TM }}$ 2000/ DNA for 24, 48, and 72 hours, respectively. (D, F and $\mathbf{H}$ ) cells transfected with SLN/ protamine/DNA nanoparticles $(50 \mu \mathrm{g} / \mathrm{mL}$ SLNs containing $15 \mathrm{wt} \%$ ODA, $4.5 \mu \mathrm{g} / \mathrm{mL}$ protamine, $3.0 \mu \mathrm{g} / \mathrm{mL}$ DNA) for 24,48 , and 72 hours, respectively, (I) negative control, and $(\mathbf{J}-\mathbf{N})$ cells transfected with SLN/protamine/DNA nanoparticles containing $0 \mathrm{wt} \%$, $5 \mathrm{wt} \%, 10 \mathrm{wt} \%, 15 \mathrm{wt} \%$, and $20 \mathrm{wt} \%$ ODA, respectively (concentrations of all types of SLNs, $50 \mu \mathrm{g} / \mathrm{mL}$ with $4.5 \mu \mathrm{g} / \mathrm{mL}$ protamine and $3.0 \mu \mathrm{g} / \mathrm{mL}$ DNA).

Abbreviations: ODA, octadecylamine; SLNs, solid lipid particles; DNA, deoxyribonucleic acid. 
of the ternary nanoparticles improved with increasing octadecylamine content in the SLNs. However, the efficiency of ternary nanoparticles containing SLNs with $20 \mathrm{wt} \%$ octadecylamine was lower than that of SLNs with $15 \mathrm{wt} \%$ octadecylamine, which might result from higher cytotoxicity of SLNs with $20 \mathrm{wt} \%$ octadecylamine. SLN/protamine/ DNA nanoparticles without octadecylamine in the SLNs showed the lowest transfection efficiency, which may be due to lack of effective interaction between their low positive surface charge $(8.7 \pm 0.3 \mathrm{mV})$ and the negatively charged cell membrane.

\section{Effect of post-transfection time}

Gene transfection was also observed using a fluorescent microscope at 24, 48, and 72 hours post-transfection. Figure 5 shows a sharp increase in Lipofectamine 2000/ DNA expression in the initial 24 hours post-transfection. Green fluorescent protein expression decreased rapidly after 24 hours. When ternary nanoparticles was used as the transfection system (culture medium containing 10\% fetal bovine serum, $50 \mu \mathrm{g} / \mathrm{mL} 15 \%$ octadecylamine-loaded monostearin SLNs, $4.5 \mu \mathrm{g} / \mathrm{mL}$ protamine, $3.0 \mu \mathrm{g} / \mathrm{mL}$ DNA), the intensity of fluorescence increased during the 72 hours post-transfection. Successful clinical gene therapy has been limited by lack of sustained gene expression. This system may be advantageous in the treatment of genetic diseases such as cystic fibrosis in which there is a need for long-acting therapeutic effects. ${ }^{35}$

\section{Effect of serum}

The gene transfection efficiency of the ternary nanoparticles and Lipofectamine 2000/DNA nanoparticles was investigated using both luciferase gene expression and flow analysis. Figure 6 shows the relative light units of luciferase gene expression for the ternary SLN/protamine/ DNA nanoparticles and Lipofectamine 2000/DNA nanoparticles with and without serum. The transfection efficiency of the ternary nanoparticles increased significantly $(P$ $<0.05, t$-test) in the presence of $10 \%$ serum, may be due to desired cell viability. However, Lipofectamine 2000/DNA nanoparticles showed less transfection activity in the presence of $10 \%$ serum $(P<0.05, t$-test $)$ than Lipofectamine 2000/DNA nanoparticles without serum, which might be attributable to interaction between Lipofectamine 2000 and proteins in serum. Flow analysis was also used to quantify gene transfection efficiency. For the ternary nanoparticles, the percentage of transfected cells was highest $(26.13 \% \pm$ $5.22 \%$ ) in the presence of serum, indicating that the ternary nanoparticles were more suitable than Lipofectamine 2000

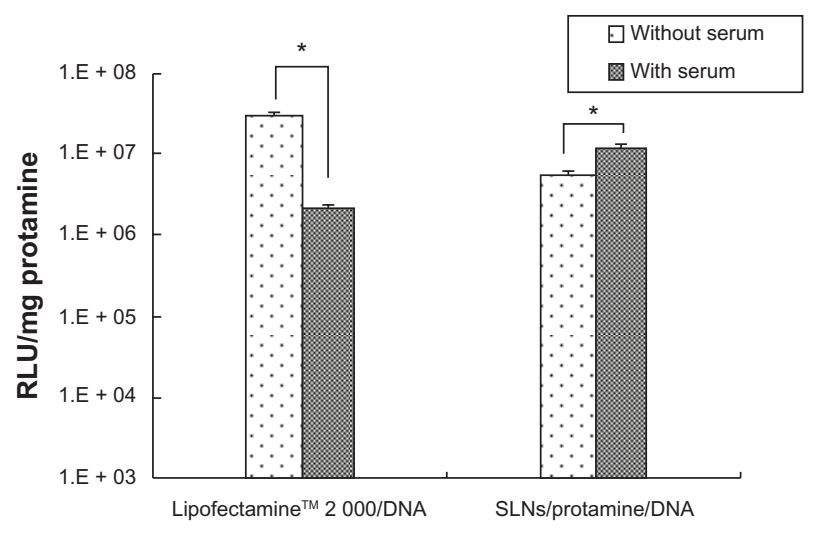

Figure 6 Effects of serum on transfection of Lipofectamine ${ }^{\text {TM } 2000 / D N A ~ a n d ~}$ SLN/protamine/DNA nanoparticles (SLNs with 15 wt\% ODA/protamine/DNA, $50: 4.5: 3, w / w / w)$ using a luminescence assay. $* P<0.05$ by $t$-test. Transfection time for Lipofectamine 2000/DNA and SLN/protamine/DNA nanoparticles was 24 and 72 hours, respectively.

Abbreviations: ODA, octadecylamine; RLU, relative light units; SLNs, solid lipid particles; DNA, deoxyribonucleic acid.

for gene transfection in vivo. Several other studies have also demonstrated that addition of polycations to cationic lipids enhances transfection activity in the presence of serum. ${ }^{36}$ It was confirmed that the gene transfection efficiency of ternary SLN/protamine/DNA nanoparticles (50:4.5:3, w/w/w) in the presence of serum was greater than that of Lipofectamine 2000/DNA nanoparticles. This result may favor future in vivo application of ternary SLN/protamine/DNA nanoparticles as a gene delivery system.

\section{Cell growth inhibition assay}

The inhibitory effects of the different nanoparticles on cell growth were determined by MTT assay. Figure 7 shows survival rates after HEK293 cells were incubated for 72 hours with ternary SLN/protamine/DNA nanoparticles in which

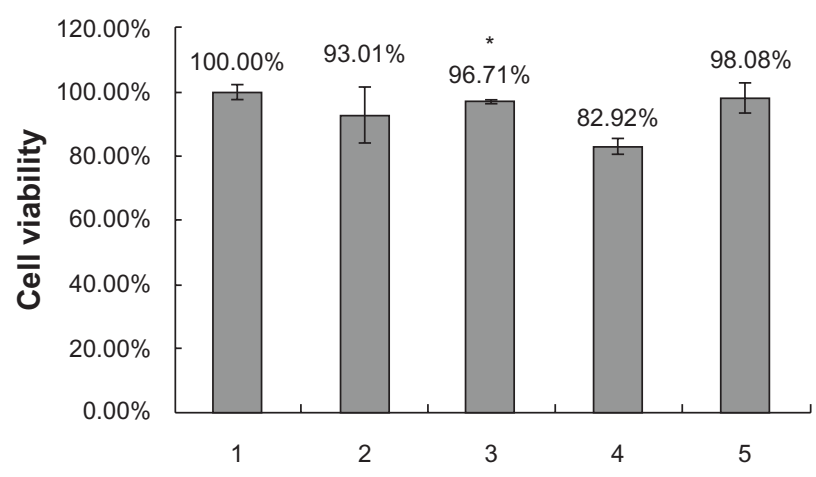

Figure 7 Cell viability by MTT test. (I) Negative control, (2) SLN/protamine/DNA nanoparticles $(50 \mu \mathrm{g} / \mathrm{mL}$ SLNs containing $15 \mathrm{wt} \%$ ODA, $4.5 \mu \mathrm{g} / \mathrm{mL}$ protamine, $3.0 \mu \mathrm{g} /$ $\mathrm{mL} \mathrm{DNA}$ ), (3) SLNs (50 $\mu \mathrm{g} / \mathrm{mL}$ SLNs containing $0 \mathrm{wt} \%$ ODA, $4.5 \mu \mathrm{g} / \mathrm{mL}$ protamine, 3.0 $\mu \mathrm{g} / \mathrm{mL}$ DNA), (4) Lipofectamine ${ }^{\mathrm{TM}}$ 2000/DNA nanoparticles $(6 \mu \mathrm{g} / \mathrm{mL}$ Lipofectamine 2000, $3.0 \mu \mathrm{g} / \mathrm{mL} \mathrm{DNA})$, and (5) protamine/DNA binary nanoparticles $(4.5 \mu \mathrm{g} / \mathrm{mL}$ protamine, $3.0 \mu \mathrm{g} / \mathrm{mL}$ DNA). ${ }^{*} P<0.05$ comparing it with Lipofectamine.

Abbreviations: ODA, octadecylamine; SLNs, solid lipid particles; DNA, deoxyribonucleic acid. 


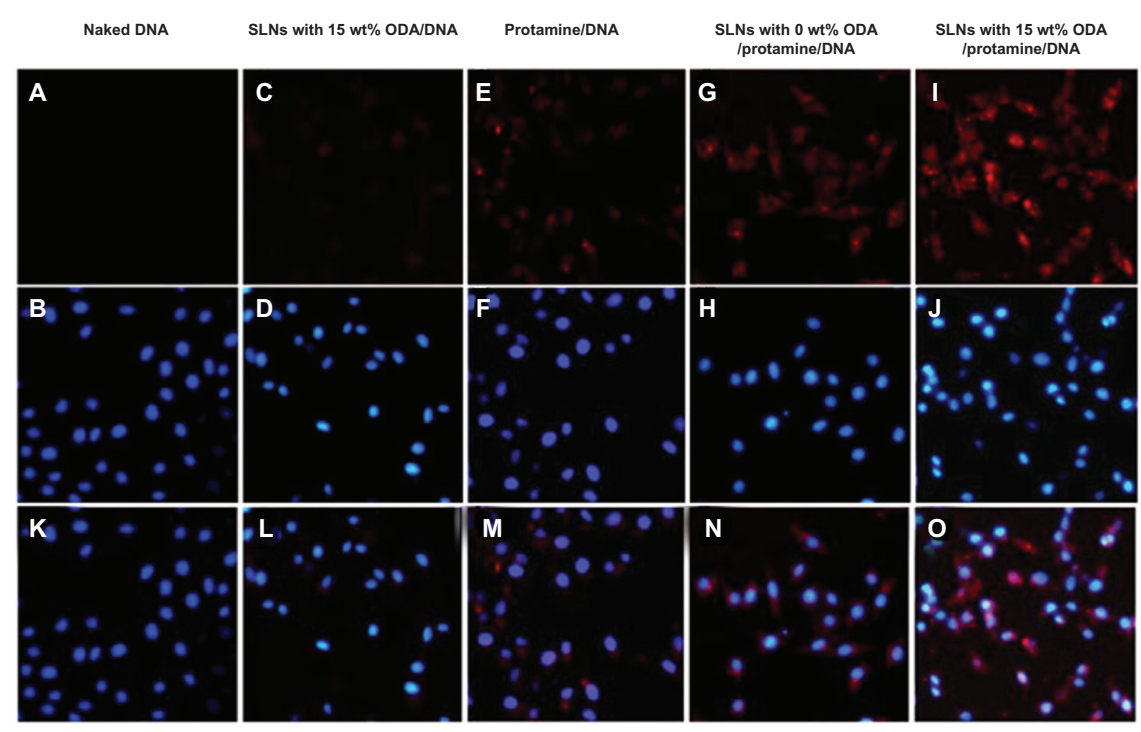

Figure 8 Fluorescent images after cells were incubated with fluorescent nanoparticles for 6 hours. The cells were treated with Hoechst 33342 (blue) to detect the nucleus and DNA was labeled by ROX (red).

Notes: (A) is naked DNA. (C) is the DNA of SLNs with I5\% ODA/DNA. (E) is the DNA of Protamine/DNA. (G) is the DNA of SLNs with 0 wt ODA/protamine/DNA (B, D, F, H, J) are the nucleus corresponding to the above group. (I) is the DNA of SLNs with I5\% Wt DA/protamine/DNA. (K-O) are the merged images of DNA with nucleus.

Abbreviations: ODA, octadecylamine; SLNs, solid lipid particles; DNA, deoxyribonucleic acid.

SLNs contained $15 \mathrm{wt} \%$ octadecylamine. Cell viability using all the gene delivery systems was greater than $90 \%$ after 72 hours of incubation. An octadecylamine content of 15 $\mathrm{wt} \%$ in SLNs did not significantly increase the cytotoxicity of the ternary nanoparticles.

\section{Detection of intracellular ROX-labeled DNA by fluorescent microscopy}

A DNA trafficking study was performed to detect uptake of the nanoparticles into HEK293 cells. Figure 8 show fluorescent images of these cells after incubation with the nanoparticles for 6 hours. It can be seen that cellular uptake of DNA in the SLN/DNA nanoparticles was relatively less, which may be due to the low affinity between SLNs and DNA, and the low DNase I protection ability of SLNs (data shown in Figure 3). It seemed that protamine could condense the DNA molecules into a form that was compatible with endocytosis, and the ternary nanoparticles with SLNs containing $15 \mathrm{wt} \%$ octadecylamine could further enhance DNA uptake by cells. However, the SLN/protamine/DNA nanoparticles without octadecylamine in the SLNs were less internalized into cells, which may result from the relative low positive surface charge of the ternary nanoparticles $(8.7 \pm 0.3 \mathrm{mV})$. Figure 9 indicates the location of ROX-labeled DNA and FITC-labeled SLNs in cells after incubation with ternary SLN/protamine/DNA nanoparticles for 6 hours. It is clear that the SLNs were distributed only in the cytoplasm, while most of the DNA was conveyed to the nucleus, as seen in Figure 9D. This is possibly due to enhanced nuclear importing
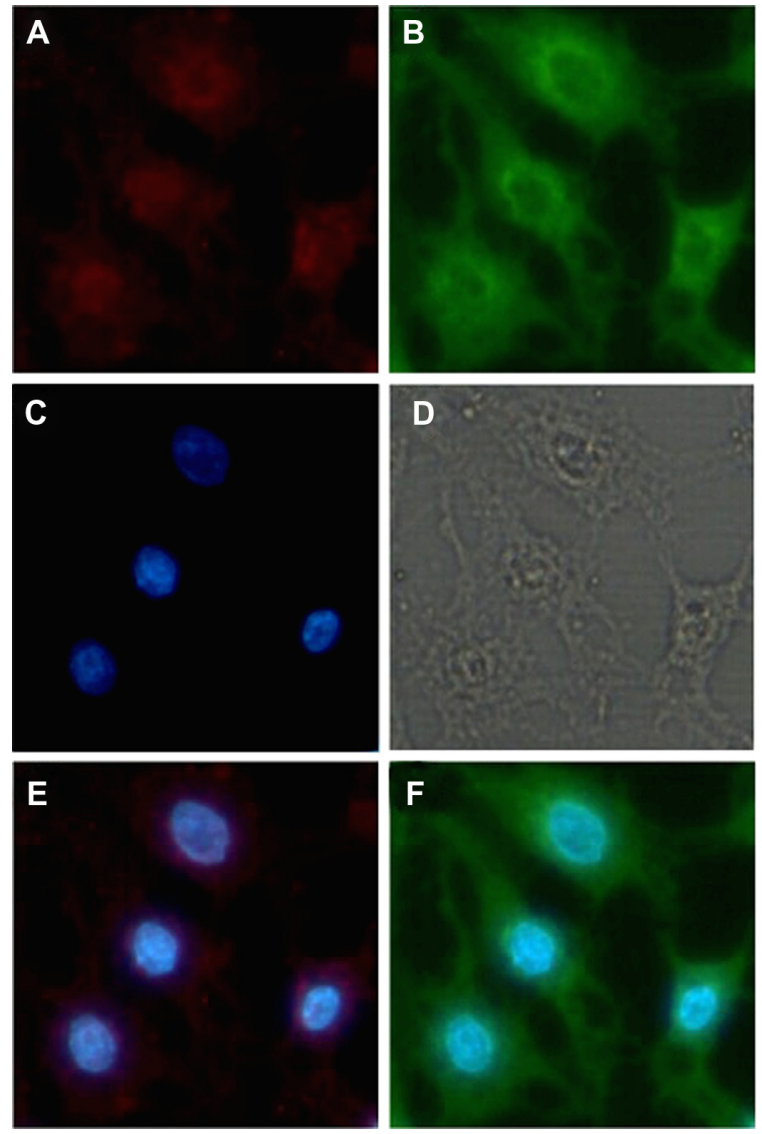

Figure 9 Fluorescent images of cells incubated with the fluorescent ternary nanoparticles for 6 hours. The cells were treated with Hoechst 33342 to detect the nucleus, SLNs were labeled with ODA-FITC (green), and DNA was labeled with ROX (red). (A) ROX-DNA, (B) ODA-FITC-loaded SLNs, (C) nucleus, (D) observed under transmitted light, (E) merged image of ROX-DNA and nucleus, and (F) merged image of ODA-FITC and nucleus.

Abbreviations: ODA, octadecylamine; FITC, fluorescein isothiocyanate; SLNs, solid lipid particles; DNA, deoxyribonucleic acid. 
of the DNA released, that promoted the transfection efficiency of this SLN-based gene delivery system.

\section{Conclusion}

In this paper, we have reported on a cationic ternary gene delivery system prepared by mixing cationic SLNs and binary protamine/DNA nanoparticles. Ternary nanoparticles containing $50 \mu \mathrm{g} / \mathrm{mL}$ SLNs with $15 \mathrm{wt} \%$ octadecylamine, $4.5 \mu \mathrm{g} / \mathrm{mL}$ protamine, and $3.0 \mu \mathrm{g} / \mathrm{mL}$ DNA had a small size (around $200 \mathrm{~nm}$ ) and showed optimal transfection efficiency in the presence of $10 \%$ serum at 72 hours post-transfection. The lipid portion appeared to be essential for efficient transfection because it enhanced entry of binary protamine/DNA nanoparticles into the cell, with protamine acting as a DNA condenser to avoid enzyme degradation and also acting as the nucleus transporter. These cationic ternary nanoparticles can express gene more sustained in the presence of serum than Lipofectamine 2000/DNA nanoparticles. Our results suggest that these cationic ternary nanoparticles have potential as an effective and long-acting nonviral vector for gene delivery.

\section{Acknowledgment}

This work was sponsored by the Zhejiang Provincial Program for Cultivation of High-Level Innovative Health talents.

\section{Disclosure}

The authors report no conflicts of interest in this work.

\section{References}

1. Wagner AM, Schoeberlein A, Surbek D. Fetal gene therapy: opportunities and risks. Adv Drug Deliv Rev. 2009;61:813-821.

2. Kassim SH, Li H, Vandenberghe LH, et al. Gene therapy in a humanized mouse model of familial hypercholesterolemia leads to marked regression of atherosclerosis. PLoS One. 2010;5:e13424.

3. Yang J, Lam DH, Goh SS, et al. Tumor tropism of intravenously injected human-induced pluripotent stem cell-derived neural stem cells and their gene therapy application in a metastatic breast cancer model. Stem Cells. 2012;30:1021-1029.

4. Morille M, Passirani C, Vonarbourg A, Clavreul A, Benoit JP. Progress in developing cationic vectors for non-viral systemic gene therapy against cancer. Biomaterials. 2008;29:3477-3496.

5. Smith AE. Viral vectors in gene therapy. Annu Rev Microbiol. 1995;49: 807-838.

6. Pathak A, Patnaik S, Gupta KC. Recent trends in non-viral vectormediated gene delivery. Biotechnol J. 2009;4:1559-1572.

7. Godbey WT, Wu KK, Mikos AG. Tracking the intracellular path of poly(ethylenimine)/DNA nanoparticles for gene delivery. Proc Natl Acad Sci U SA. 1999;96:5177-5181.

8. Yamano S, Dai J, Yuvienco C, Khapli S, Moursi AM, Montclare JK. Modified Tat peptide with cationic lipids enhances gene transfection efficiency via temperature-dependent and caveolae-mediated endocytosis. J Control Release. 2011;152:278-285.

9. Islam MA, Yun $\mathrm{CH}$, Choi YJ, et al. Accelerated gene transfer through a polysorbitol-based transporter mechanism. Biomaterials. 2011;32:9908-9924.
10. El-Sayed A, Masuda T, Khalil I, Akita H, Harashima H. Enhanced gene expression by a novel stearylated INF7 peptide derivative through fusion independent endosomal escape. $J$ Control Release. 2009;138: 160-167.

11. Panyam J, Labhasetwar V. Biodegradable nanoparticles for drug and gene delivery to cells and tissue. Adv Drug Deliv Rev. 2003;55: 329-347.

12. Vighi E, Montanari M, Ruozi B, Tosi G, Magli A, Leo E. Nuclear localization of cationic solid lipid nanoparticles containing protamine as transfection promoter. Eur J Pharm Biopharm. 2010;76: 384-393.

13. Junghans M, Loitsch SM, Steiniger SC, Kreuter J, Zimmer A. Cationic lipid-protamine-DNA (LPD) nanoparticles for delivery of antisense c-myc oligonucleotides. Eur J Pharm Biopharm. 2005;60: 287-294.

14. Lo SL, Wang S. An endosomolytic Tat peptide produced by incorporation of histidine and cysteine residues as a nonviral vector for DNA transfection. Biomaterials. 2008;29:2408-2414.

15. Arthanari Y, Pluen A, Rajendran R, Aojula H, Demonacos C. Delivery of therapeutic shRNA and siRNA by Tat fusion peptide targeting BCRABL fusion gene in chronic myeloid leukemia cells. J Control Release. 2010;145:272-280.

16. Tros DIC, Sun Y, Duzgunes N. Gene delivery by lipoplexes and polyplexes. Eur J Pharm Sci. 2010;40:159-170.

17. Chan CL, Majzoub RN, Shirazi RS, et al. Endosomal escape and transfection efficiency of PEGylated cationic liposome-DNA nanoparticles prepared with an acid-labile PEG-lipid. Biomaterials. 2012;33: 4928-4935.

18. Martinez GJ, Csaba N, Fischer S, et al. Surface coating of PLGA microparticles with protamine enhances their immunological performance through facilitated phagocytosis. J Control Release. 2008;130: 161-167.

19. Braun RE. Packaging paternal chromosomes with protamine. Nat Genet. 2001;28:10-12.

20. Thu MS, Bryant LH, Coppola T, et al. Self-assembling nanoparticles by combining ferumoxytol, heparin and protamine for cell tracking by magnetic resonance imaging. Nat Med. 2012;18:463-467.

21. Vighi E, Montanari M, Ruozi B, Iannuccelli V, Leo E. The role of protamine amount in the transfection performance of cationic SLN designed as a gene nanocarrier. Drug Deliv. 2012;19:1-10.

22. Sorgi FL, Bhattacharya S, Huang L. Protamine sulfate enhances lipidmediated gene transfer. Gene Ther. 1997;4:961-968.

23. Chen J, Yu Z, Chen H, Gao J, Liang W. Transfection efficiency and intracellular fate of polycation liposomes combined with protamine. Biomaterials. 2011;32:1412-1418.

24. Liu J, Guo S, Li Z, Liu L, Gu J. Synthesis and characterization of stearyl protamine and investigation of their nanoparticles with DNA for gene delivery. Colloids Surf B Biointerfaces. 2009;73:36-41.

25. Mehnert W, Mader K. Solid lipid nanoparticles: production, characterization and applications. Adv Drug Deliv Rev. 2001;47:165-196.

26. Nassimi M, Schleh C, Lauenstein HD, et al. A toxicological evaluation of inhaled solid lipid nanoparticles used as a potential drug delivery system for the lung. Eur J Pharm Biopharm. 2010;75:107-116.

27. Yuan H, Miao J, Du YZ, You J, Hu FQ, Zeng S. Cellular uptake of solid lipid nanoparticles and cytotoxicity of encapsulated paclitaxel in A549 cancer cells. Int J Pharm. 2008;348:137-145.

28. Yuan H, Zhang W, Du YZ, You J, Hu FQ. Ternary nanoparticles composed of anionic lipid nanoparticles/protamine/DNA for gene delivery. Int J Pharm. 2010;392:224-231.

29. Vighi E, Montanari M, Hanuskova M, Iannuccelli V, Coppi G, Leo E. Design flexibility influencing the in vitro behavior of cationic SLN as a nonviral gene vector. Int J Pharm. 2013;440:161-169.

30. Yuan H, Chen J, Du YZ, Hu FQ, Zeng S, Zhao HL. Studies on oral absorption of stearic acid SLN by a novel fluorometric method. Colloids Surf B Biointerfaces. 2007;58:157-164. 
31. Heinz H, Farmer BL, Pandey RB, et al. Nature of molecular interactions of peptides with gold, palladium, and Pd-Au bimetal surfaces in aqueous solution. J Am Chem Soc. 2009;131:9704-9714.

32. Fischer FD, Waitz T, Vollath D, Simha NK. On the role of surface energy and surface stress in phase-transforming nanoparticles. Prog Mater Sci. 2008;53:481-527.

33. Harada-Shiba M, Takamisawa I, Miyata K, et al. Intratracheal gene transfer of adrenomedullin using polyplex nanomicelles attenuates monocrotaline-induced pulmonary hypertension in rats. Mol Ther. 2009; 17:1180-1186.
34. Rorke S, Keeney M, Pandit A. Non-viral polyplexes: scaffold mediated delivery for gene therapy. Prog Polym Sci. 2010;35:441-458.

35. Aitken ML, Bellon G, De Boeck K, et al. Long-term inhaled dry powder mannitol in cystic fibrosis: an international randomized study. Am J Respir Crit Care Med. 2012;185:645-652.

36. Obata Y, Suzuki D, Takeoka S. Evaluation of cationic assemblies constructed with amino acid-based lipids for plasmid DNA delivery. Bioconjug Chem. 2008;19:1055-1063.
International Journal of Nanomedicine

\section{Publish your work in this journal}

The International Journal of Nanomedicine is an international, peerreviewed journal focusing on the application of nanotechnology in diagnostics, therapeutics, and drug delivery systems throughout the biomedical field. This journal is indexed on PubMed Central, MedLine, CAS, SciSearch $®$, Current Contents $® /$ Clinical Medicine,

\section{Dovepress}

Journal Citation Reports/Science Edition, EMBase, Scopus and the Elsevier Bibliographic databases. The manuscript management system is completely online and includes a very quick and fair peer-review system, which is all easy to use. Visit http://www.dovepress.com/ testimonials.php to read real quotes from published authors.

Submit your manuscript here: http://www.dovepress.com/international-journal-of-nanomedicine-journal 